\title{
Transforming learning for the smart learning paradigm: lessons learned from the Palestinian initiative
}

\author{
Zuheir N. Khlaif ${ }^{*}$ (D) and Shahid Farid ${ }^{2}$
}

\author{
*Correspondence: zuh.khlaif@gmail. \\ com \\ ${ }^{1}$ Instructional Systems Technology, \\ Indiana University, Bloomington, \\ USA \\ Full list of author information is \\ available at the end of the article
}

\begin{abstract}
The purpose of the study is to identify the variations taking place in the Palestinian educational system due to implementations of smart learning project in the Palestinian public schools. In addition to this exploration of the strengthens and weaknesses of the smart learning project is also done. A qualitative approach has been adopted to achieve the purpose of the study. Different tools were used for data collection from 30schools across the country including observations, interviews, and focus group discussion. The findings of the study revealed several changes of teachers' roles and schools' administrators associated with the implementation of smart learning project in Palestine. This study contributes in a fashion to assist other educationists and researchers to review the methods of learning and teaching in the country. Besides significance of smart learning, a confined attention is given to state of the art literature regarding adoption and promotion of smart learning in developing countries like Palestine.
\end{abstract}

Keywords: Smart learning, Smart learning environment, Mobile technology

\section{Introduction}

The world is transforming into a digital world which comprises of real and digital worlds (Zhu et al., 2016). No doubt with the advancement of Information and Communication Technology (ICT), this universe is becoming global village, and universities are adopting the latest information and communication tools to transform this universe into global village. Information and communication technologies undoubtedly bring important changes in all human activities and also into the educational system in the developed countries (Shraim \& Khlaif, 2010). Development in advance technology broadens the learning environment place, the content, and makes the learning better through establishing new digitalized educational environment (Groff, 2013). It is a convenient tool not only for learning and teaching but for training as well. This mode of learning has provided education with enormous and novel opportunities by extending the potential to reach the new learners for delivering education (Arif et al. 2015, Farid et al. 2018).

Advancement in ICT has not only reshaped the traditional learning settings but also puts potential on creativity among students, integration of different pedagogical strategies (Serdyukov \& Serdyukov, 2017. Various exciting possibilities associated with ICT have been emerged to reshape students' learning behaviors and teachers' teaching methods (Kinshuk

(c) The Author(s). 2018 Open Access This article is distributed under the terms of the Creative Commons Attribution 4.0 International License (http://creativecommons.org/licenses/by/4.0/), which permits unrestricted use, distribution, and reproduction in any medium, provided you give appropriate credit to the original author(s) and the source, provide a link to the Creative Commons license, and indicate if changes were made. 
et al., 2016). The ways of learning are changing, people can learn anytime, anywhere, formally and informally either in classroom or at home (Liu et al., 2017, Gros, 2016).

Hwang (2014) mentioned that smart learning can support learners with new experience of easy, effective, and engaged learning. Smart learning integrates formal and informal learning to establish adaptive learning environment for supporting individual learners with real-time andseamless experiences (Kinshuk et al. 2016). It has been claimed by Spector (2014) that smart learning is effective, efficient, and establishes learning environment. It is the environment that can be adapted to learner's needs and personalized instruction and learning support.

Therefore, the purpose of this study is to explore the paradigm shift happened in the Palestinian educational system by implementing Smart Learning project (hereafter SL) and to familiarize the strengths and weaknesses of the project through the SWOT analysis to reflect the evolution of the current implementation strategies of SL by analyzing the case of Palestine. Moreover, opinion of experts, academicians and researchers (of the domain) may lead our effort to the point which may be helpful for the educational institutions and related government agencies (like ministry of education) in promoting smart learning to enhance the literacy rate in the Palestine.

The motivational factors of this study include dire need for the adoption of e-learning and smart technological resources in education to encounter the innovative educational changes. As state-of-the-art literature is deficient to address transformation of cutting-edge technology of smart learning project in the Palestine. Therefore, this study contributes in a way to assist other educators and researchers to review the methods of learning and teaching. Finally, a road map will be formulated for the developing countries like Palestine that are in the process of ameliorating their education system by deploying technological innovations.

\section{Literature review}

Teaching paradigms are shifting from teacher-centered teaching to student-centered learning by adopting ubiquitous learning (u-learning) and social learning The idea of presenting new environments, contexts and opportunities for learning made new thoughts for developing learning towards 'E-learning' and Smart technology (Woollard, 2011). According to Woollard (2011), the world of e learning is conquered by a lot of technical definitions, abbreviations and other novel words and acronyms. E-learningis regarded as any kind or form of teaching, tutoring or training that satisfies the needs of learners in different ages and abilities through electronic multimedia resources, internet, computers, mobiles and any other technology-based device (Woollard, 2011). Moreover, the concept of e-learning can also be defined as the ability of learner to learn in way or type that is different from conventional or ordinary learning.

\section{Smart learning concept}

Scholars, educators, and researchers contend that a new learning paradigm, smart learning, is emerging as a convergence concept of social learning and u-learning (Adu \& Poo, 2014; Zhu et al., 2016). There is no agreement between researchers and educators about a clear definition of SL (Zhu et al., 2016). Practitioners and researcher can 
find common and prime elements of smart learning. In addition to efficient utilization of smart devices the broad spectrum of smart learning encompasses nature of learning environment like infrastructure, technological devices, pedagogical, and learners' profile. For instance, in Korea, the government, academia, and the educational industry considers SL as a learning paradigm focusing on human and content rather than devices and as well as an effective, intelligent tailored-learning based on advanced IT infrastructure (Kim et al. 2013). As per Korean definition, SL is a new environment of learning utilizing latest IT and network infrastructure combined with novel learning and teaching strategies. SL, the emerging learning environment, allows learners to use all available learning devices and social media round the world and round the clock.

Hwang 2014, (p. 6-7) claimed that only three features are vital to define smart learning environment including context-aware, adaptive support, and adaptive interface. Furthermore, Zhu et al. (2016) proposed a framework for smart education and described ten Key features that define smart learning:

1. Location-aware: in smart learning the real time location is major requirement of the systems to adapt the content and situation of the learner;

2. Context-aware: exploring different activity scenarios and information;

3. Socially-aware: sensing social relationships;

4. Interoperable: setting standards for different resources, services and platforms;

5. Seamless connection: providing continuous service when any device connects;

6. Adaptable: pushing learning resources according to access, preference and demand;

7. Ubiquitous: predicting learner demands until clearly expressed by providing visual and transparent access to learning resources and services;

8. Whole record: recording learning path data to data repository and analyze in depth, then provide reasonable assessment, suggestions and pushing on-demand service;

9. Natural interaction: transferring the senses of multimodal interaction, including position and facial expression recognition;

10. High engagement: Engagement in multidirectional interactive learning experiences in technology-enriched environments.

The philosophy of SL learning is not only improving learning by using advance technology, but it also concerns about personalization and adaptation of the real life learning based on the location. The design of smart learning environment should take into consideration various factors such as context, socio-cultural characteristics of the formal and informal learning, and cultural resources (Gros, 2016). The findings of extensive literature review revealed that learning in SL environment is a merge of both contextual and social activity mediated by technology focusing on using new pedagogy.

\section{The smart learning world wide}

Technology enriched learning has made teaching effective and significant. Integration of ICT in educational system has immensely revolutionized the teaching methodology that revamps the idea of teaching and learning methods (Kay, 2009). The Smart Learning (SL) is a kind of technology-based learning or a recently developed educational implementation of technological resources and electronic tools for enhancement of learning and teaching 
strategies. Reports published by Research and market (2017) mention that the market size of smart education and learning is expected to grow from USD 193.24 Billion in 2016 to USD 586.04 Billion by 2021, at a Compound Annual Growth Rate (CAGR) of 24.84\%. The base year considered for the study is 2015 and the forecast period has been determined from 2016 to 2021. According to the report, Smart Learning is in great demand of its services, software, hardware, and educational equipment. The report emphasizes on a wide range of products used in the smart learning environment including Simulation Based Learning hardware, Interactive Projectors, Interactive Whiteboard, Open Source software, Learning Management Systems/Learning Content Management Systems, and Mobile education application.

Many of SL initiatives have been implemented in the world. For example, Malaysia started Smart Schools in 1997; all the schools should be transformed into smart schools by 2020 (Ibrahim et al., 2013). The Malaysian Smart Schools focuses on the continuously developing its professional staff, its educational resources, and its administrative capabilities. Based on the vision of Ministry of Education in Malaysia, smart schools will allow school to adapt the changing conditions to prepare students for life in the Information Technology Age. The objectives of Smart Schools in Malaysia are to produce technology-literate workforce and to provide opportunities to enhance individual strengths and abilities in twenty-first century. The main two criterion for successful of smart schools are well-designed technical support and skilled staff (Galil, 2014).

The smart school project in Iran, with inspiration from the original idea in Malaysia, was launched in 2004 in four high schools in the capital city of Tehran (Attaran et al,, 2012). Smart schools in Iran have been proposed as a solution to increase the capabilities of the new generation in the era of ICT (Taleb \& Hassanzadeh, 2015).

Singapore is another Southeast Asian country that uses ICT methods in education. In 1997, the first large-scale initiative was developed in order to make use of ICT in education infrastructure. Moreover equipping teachers with the skills they need for the use of ICT in their lessons. The second major project for the use of ICT in education (2003-2008) was more about infrastructure and the integration of ICT with teacher training schools. Finally, the third Master Plan (2009-2014) on the integration of ICT with curriculum emphasizes training and evaluation. The plan is based on the belief that ICT, encourages students in any place and time to search for self-learning and experiential learning and increases them for the twenty-first century learning (Koh and Lee, 2008).

In United Arab Emirates, the Mohammed Bin Rashid Initiative for Smart Learning is a program that implements Information and Communication Technology (ICT) in public schools of the ministry of education in UAE and intends to cover all the governmental schools over the next five years. It produces an innovative learning setting in schools through "smart classes", supported with smart boards and by provision of tablet PC and high-speed 4G networks. This initiative also provides teachers with modern laptops and specialized training programs to maintain the success of the project (Galil, 2014).

\section{SWOT analysis of smart learning}

The SWOT model (Strengths, Weaknesses, Opportunities, and Threats) enables to analyze the actual stage of SL implementation in various schools to provide suitable suggestions for enhancing and guiding the implementation stage into the best practice of SL 
in the Palestinian public schools. In addition it sets recommendations for some of the technical and technological challenges in Palestinian public schools. The SWOT analysis has long been acknowledged in many industries and educational fields as a useful analytical tool for developing strategies (Felton, 2004). SWOT is an acronym for Strengths, Weaknesses, Opportunities and Threats. The 'opportunity' and 'threat' should both focus on possible future of analyzed situation. It is important to consider various solutions after examining the results of SWOT analysis. SWOT method can be used during the design, development, and implementation stages of any project. Also, SWOT is a convenient tool for the evaluation stage to have an initial idea of the future consequences.

The authors have agreed that SWOT analysis is an essential step for analysis of various factors before implementing the project on a large-scale at any institution. As the success or failure of a technological initiative will directly relate to the quality of strategic thinking that underpins it. It is thus substantial to have clear vision and mission before the implementation process. SWOT analysis will help decision makers in the MOEHE to decide about opportunities with respect to smart learning implementation to choose the appropriate policy issues related to it and should be considered: improvement of the learner's knowledge, learning outcomes, efficiency of the teaching and learning process, and the reductions of costs.

\section{The context of the study}

Palestine is in the Middle East region and is described as a conflict zone with mobility restriction (Khlaif, 2018b; Shraim \& Khlaif, 2010). Palestine is divided into small areas separated by security checkpoints that adversely affect the educational system (Shraim \& Khlaif, 2010). There are 2963 public schools in Palestine. Around 200 of Palestinian schools are located behind the separation wall and checkpoints which means that teachers need to get permission to enter the area and sometimes owing to security reasons they are unable to get permission. The Ministry of Education (hereafter MOEHE) has been using technology in the educational system to support effective learning since 1999. The MOEHE started training the teachers about the literacy of computer and to design educational activities by using computer and its accessories in 1999 (MOEHE, 2000). In Palestine technological innovations have become crucial due to Lack of resources and training to meet the growing demand of education and to overcome the mobility restrictions (Shraim \& Khlaif, 2010). Technology integration is the most significant implication in conflict zones with shortage of educational resources (Risler, 2009). Palestinians consider development of technology as an essential tool for their survival, mitigating their daily difficulties, facilitating the emergencies, improving the equity of using technology among students in both public and higher education (Saidam, 2007; Shraim \& Khlaif, 2010). Consequently, the MOEHE has adapted and implemented different technological innovations in the educational system to improve the communication between teachers, students, and parents along with enlightening the equity and quality of education in math, science, English, and Arabic language (Khlaif, 2018a). The comprehensive list of these initiatives comprises of Smart Learning (2017), Digitalization of Education (2016), AbjadNet (2013), NetKetabi (Interactive book, 2012), LTD (Leadership and Teacher Development program, 2012), Model Schools Network (2007), Intel for Education (2008), and Seed (2012) (MOEHE, 2017). These projects are funded by national and international organizations. 
In addition to the technological initiatives, MOEHE in Palestine adapted and implemented various projects to be used in the teaching process to improve teaching methods such as Learning by Doing, Learning by Playing, Learning by Exploring, Learning by Music, Project-Based Learning, and Drama in Education (MOEHE, 2014). These projects are funded by the MOEHE and by national and international non-profit organizations.

A cooperation program 2008-2011"e-Learning Curriculum in Primary and Secondary Education" with Belgium was implemented. The main outcome of the Belgian project was the enrichment of educational platforms with technological activities (elearn.edu.ps) likePalestinian e_School Portal (eschool.edu.ps), providing schools with tablets, and training the teachers to use tablets into their practice (Khlaif, 2018b; Khlaif, 2018a).

In 2017, the Internet World Stats mentioned a 61.3\% penetration rate of Internet usage among Palestine population of 4.93 million. The trend of these statistics shows that the digital gap between Palestine and other countries is narrowing over time. Several national and international agencies, such as Cisco, the Japan International Cooperation Agency, the British Council, USAID, the Belgian government, the Welfare Association, the Palestinian Academic Network and the Palestinian Information Technology Association of Companies, are currently active in Palestine, supporting and accelerating the adoption of e-learning and technology-assisted learning (Mikki \& Jondi, 2010). According to the third national strategic plan 2017-2022, the MOEHE will focus on student-centered learning approach by adapting new technology initiatives in public schools and new programs for teachers' professional development programs (MOEHE, 2017).

\section{Emergence of smart learning in Palestine}

Over the years, new technologies have revolutionized the educational system in Palestine, yielding new learning delivery methods. In Palestine as well as worldwide, ICT is the umbrella of integrating technology into teaching practice.

The MOEHE started using ICT officially in 2000. ICT support of education relies on usage of computer, Video, Over Head Projectors, desktop computers, etc. In 2004, with help of national and international organization the MOEHE established networks in computer labs of schools to mitigate the difficulties faced by the school administrations. At that time, some individual technological initiatives emerged regarding usage of technology and broadband internet. These initiatives focused on providing teachers with technological activities and training the teachers to use technology into their practice (MOEHE, 2004). In 2008, e-learning project was implemented to support education by using laptops and internal networks. Although the utilization of galaxy 3 started but still students were time and space bound (Khlaif, 2018a). Even though schools had tablets but the students can only make use of these devices in limited time. Teachers developed their teaching methods by using these devices outside the classroom and in the break time during the school day. With the emergence of low-cost embedded sensors and more importantly, sensor-equipped smart mobile devices, the MOEHE implemented the digitalization of education initiative with the help of national organization such as Paltel, PSD (Partners for Sustainable Development), and local community. Some international organizations are involved in this initiative by supporting schools with interactive projectors (AMIDEAST, USA; Belgian Cooperation Council; China) and professional development of teachers (AMIDEAST). 
Recently in Palestine, the SL paradigm, which combines u-Learning and social learning, has emerged since 2016. The evolution of Smart Learning is expected to improve the educational environment to an advanced level regarding devices, networks, education programs etc. However, discussions on Smart Learning have just begun in Palestine, and the related studies are insufficient.

The smart learning project in Palestine is including 50 middle schools as a pilot project. In coming years the project will be carried over the country. At the beginning of the academic year 2015-2016 some public schools started to implement Smart Learning project (SLP) in grade fifth and sixth aiming to replace the teaching and learning practices in the traditional classroom with the best technological practices.

\section{Components of smart learning in Palestine}

Based on the official documents from MOEHE in Palestine and field trips, SL in Palestine has three core elements teachers, learners, and technology respectively. On the individual level, these elements are subdivided and specified. Teacher's presence incorporates student-centered learning styles, personalized and collaborative pedagogical models to carry out learning activities in technology facilitated environments and by

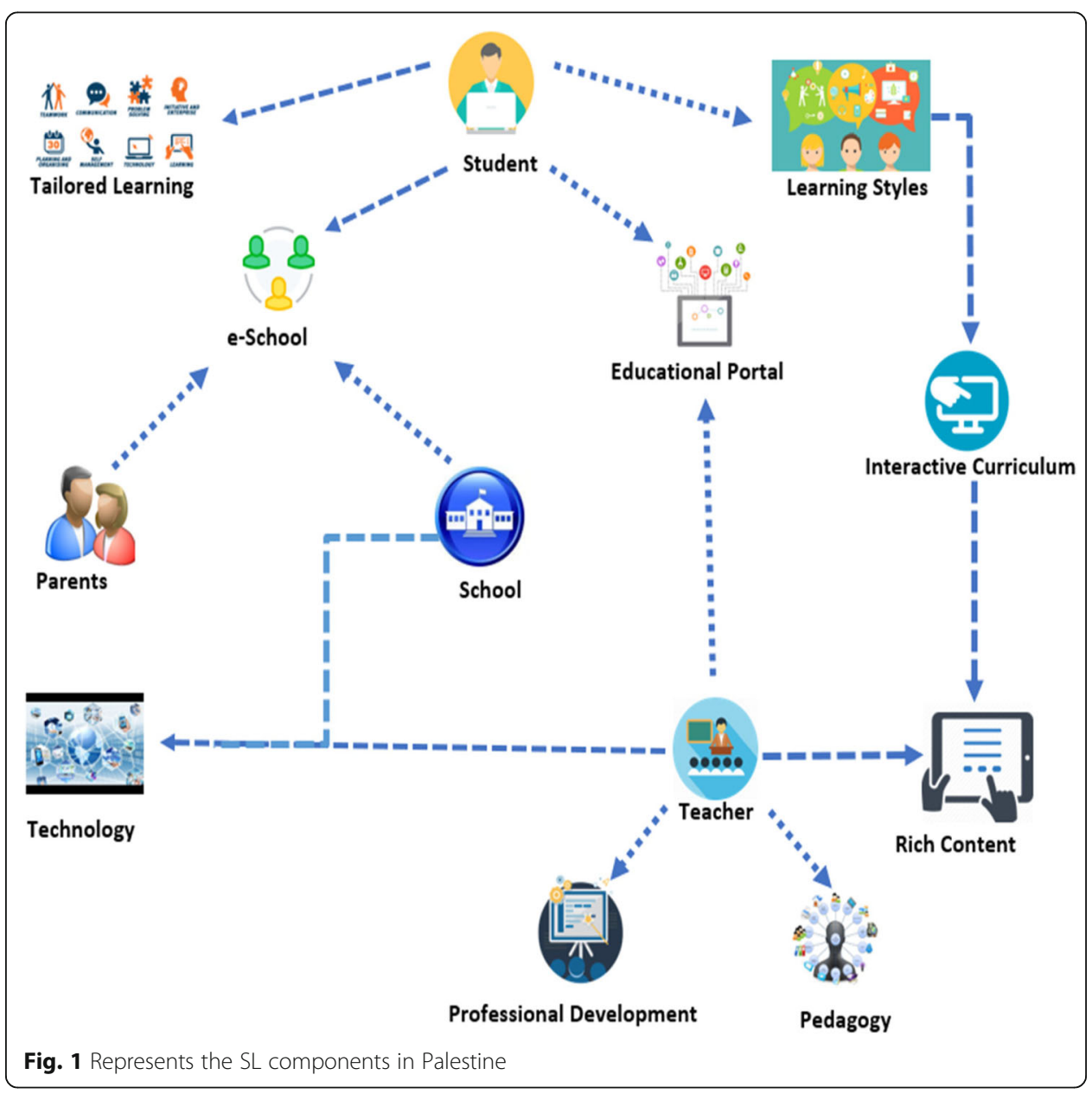


facilitating the learning process by promoting students. Figure 1 represents the components of SL project in the Palestinian education system.

\section{Research questions}

Two research questions have been driven the study:

- What are the strengths and weaknesses of Smart Learning project in Palestine?

- What changes took place in the learning environment by implementing Smart Learning project in the Palestinian schools?

\section{Research method}

Selection of an appropriate research method is one of the critical and vital tasks to achieve the formulated objectives. This study adopted qualitative research method to collect data by visiting various educational institutions. This activity took seven-months to observe the natural settings and implementation of the teaching-learning procedures, with a focus on advance technology, tablets, usage in the teaching-learning process. Interviews were conducted with the schools' principals, some teachers who used technology in teaching, and a focus group of teachers in a professional development workshop. Each of the interview was recorded and notes were also taken in the field trips.

\section{Participants of the study}

Thirty schools out of fifty agreed to participate voluntarily in the current study. The participation in the study allowed the researchers to visit the schools, meet with teachers, and observe classrooms. During the study 30 principals, 75 teachers were interviewed from different backgrounds, and attended three sessions of professional development workshops.

\section{Data collection}

Observations, interviews, and focus group discussion were the main sources of data collection in this study.

\section{Data analysis}

Strengths of smart learning

Availability of infrastructure Smart Learning relies on the present wireless, Internet and multimedia technology and of course mobile devices like tablets and smart phones which are used to a greater extent for wide spectrum of each day activities. These activities range from personal interaction to social networking, from grocery shopping to banking, from popular culture to politics. With the $3 \mathrm{G}$ communication feature in Palestine, smart learning is possible. In order to implement smart learning, different learning resources should be available including digital text, graphics, images, video and audio files which are easy to copy, transport, and store. Smart learning environment facilitates teachers to design their technology integration activities individually or within design teams. The Palestinian educational environment has acceptable 
infrastructure; on average it uses $92.8 \%$ of cable, $6.4 \%$ of wireless, and $1.4 \%$ other internet networks in public schools. During the period 1999-2017, the MOEHE invested millions of dollars in infrastructure in Public schools (MOEHE, 2017).

Classroom infrastructure includes interactive projectors, tablets, and a teacher laptop to control and manage students' devices. Remote, support and management functions are included in the teachers' laptop by using iK Classroom management software to check students learning activities and to control the whole class.

Positive attitude towards the project Leaders of the schools as well as most teachers in the schools have positive attitudes towards SL program. Few schools' principals complained regarding work load and shortage of time as these principals have a lot of daily tasks they must do, and they do not have enough time to meet with teachers to discuss about the project.

Availability of digital resources Inside and outside the classroom, students can use the tablets and the digital textbooks as well as the interactive books on the devices which enable them to be more active and cultivate their ability to retain information and enjoy the class for a long period. Digital textbooks and interactive book cover four topics in fifth and sixth grades (Arabic, English, Science, and Mathematics). The classrooms were equipped with mini laptop "Netketabi" containing interactive education content along with services that promote intellectual in and out of the classroom.

Therefore, the first strength of SL is independent way of learning, enabling learner to carry books in a small device. SL project in the schools enables the teachers to use different tools to implement various educational activities by using new teaching methods. Using new teaching methods by teachers is the second strength of the SL. Likewise, the wireless network will become more widespread, devices will be fully functional, enabling the ways more efficient to access information, social interaction, and share information. Training teachers to design their activities and introduce new pedagogy in their practice is another strength of SL.

Weaknesses One of the major challenges for the project administrators and technical managers is portability of the system which states that the ability of a software system to be deployed on diverse environments (Dubey, 2012). Students may utilize diverse nature of devices containing various platforms (Operating Systems) or student may transfer their software to a new digital device. Professional development workshops focused on technical issues more as compared to instructional assistance. Teachers in the interviews explained their needs about more workshops on new teaching strategies.

Content area is one of the weaknesses of the Palestinian SL project. Various companies are working on development of the interactive content for tablets. Therefore, there is lack of organizations to control the high-quality content necessary for effective tailored learning. SL project is using a school network which has a low bandwidth, it cannot guarantee that all the students' devices in the classroom work at the same time and with proper internet. This issue has been observed in various schools. For example, in one school, the devices worked on the network for $20 \mathrm{~min}$, after that the devices were disconnected from the network. Live communication among student-student and teacher-student was weak because 
of the weakness of the school's network. Not only the communication was delayed because of the network, but also, students did not get the shared activities and exams on time.

In the focus group sessions, teachers mentioned that there is no standard for technology integration activities and there in no clear vision regarding common regulations, or standard for the smart learning project in the schools. Teachers reported that there is misunderstanding of Smart learning in the Palestinian schools.

One of the weaknesses of the SL project is the lack of cross institutional collaboration with local universities. Lack of guideline for students' assessment is another weakness of the project. Old teachers feel difficulty in accepting SL. Through classroom observations and schools' visits, researchers noticed technological barriers including charging the devices as well as the weaknesses of e-content development; difficulties in overcoming initial implementation problems and lack of experience in using technology. The cultural factors are another weakness of the project which include: unfamiliarity with the Internet and related technologies that results in lack of appreciation and understanding of smart learning and its benefits and raises opposition to the adoption of new pedagogical strategies (e.g. flipped classroom, learning by playing, etc.).

Opportunities Initiation of the traditional professional development programs modernize learning by design approach and equip teachers with suitable skills and knowledge. Teachers reported that they have opportunity for professional development on using new teaching methods in their practice as well as to work together to design their technology integration activities. Many teachers reported that they are engaged with design teams for technology integration activities. They got opportunity to learn new technological and instructional skills. They mentioned that they have opportunity to integrate different pedagogical strategies and tablets into classroom instruction.

All the schools that are involved in the SL project have opportunity to share their teachers' experience of teaching in the SL program on social media or in the regular meetings in the directorates.

Local companies and national non-profit organizations have opportunities to invest in the project through designing interactive content and professional development for teachers about technology integration. New companies emerged to work on development of content which gave opportunities for selling their products.

In the interviews and focus group sessions teachers reported about the opportunities provided to students including equity with students from big cities to use technology into learning as well as sharing their skills and knowledge on social media websites. Moreover, teachers do not need to carry a bag full of heavy books. Collaboration with local universities was observed in limited schools which provide teachers opportunities to work with expertise for integrating technology into their practice. In addition, SL project mitigates the daily difficulties that teachers confront due to the separation wall and checkpoints. Teachers have opportunity to share their experience and activities on social media websites.

Threats As Internet is one of the essential mean of deploying SL that encounters various security and privacy threats (Farid et al., 2017). The privacy of students is important for parents. Most of the schools in the project share the activities and the 
children pictures without any permission from students or their parents. Moreover, due to multi-user environment having shared information and accessthrough the Internet makes its security sensitive especially cyber security. This is a sensitive situation for students in a conflict zone with a specific culture. School principals reported in the interviews sessions that parents were uncomfortable in sharing their kids' activities and other information like pictures on social media.

Standardization is another threat of SL project especially about assessment and sharing content. Older teachers resist in implementing the activities in their classroom. Furthermore, checkpoints and separation wall have negative influence on the SL project. The security procedures on the ground prevent the Palestinian educational system to access the high tech and to achieve 4G, which prohibited schools to utilize high-speed internet.

Analysis of the results In terms of the first research question: What are the strengths and weaknesses of Smart Learning project in Palestine? The results of the study show that the strengths of the Palestinian Smart learning are its acceptable infrastructure, devices, acceptance from local community, and development of new teaching methods. The implications for each result are shown in Table 1.

Local community and national non-profit organizations funding the project will ensure the sustainability of the project through up gradation of the current devices. The infrastructure, professional development of teachers and the content controlled by the MOEHE will ensure the systematic development of content and development of new teaching methods.

Through cooperation between the MOEHE and donors, weaknesses such as outdated devices could be replaced by acceptabl and unified software on these devices. Furthermore, lack of high-quality of content, low bandwidth can be minimized. In terms of other weaknesses, the MOEHE could minimize their impact by adopting a solid strategy with clear vision to implement the SL project.

Table 1 Strengths, Weaknesses, Opportunities, and Threats of the SL project

\begin{tabular}{ll}
\hline Strengths & Weaknesses \\
- Most of the schools' principals and teachers & - Different types of devices with different \\
operating systems. & - Lack of high-quality of content \\
- Acceptable infrastructure in the schools & - Low bandwidth of the school network \\
- Proliferation of digital technology in the schools & - Lack of guideline, vision, and goal \\
- Interactive book for four topics & - Lack of collaborative with local universities \\
- Availability of Wi-Fi Internet and 3G & - Culture of teachers \\
- Emerge new teaching methods among teachers & \\
- Acceptance of local community to support the & \\
project financially. & \\
- High percentage of using Internet & Threats \\
Opportunities & - Checkpoints and the separation wall \\
- High providing schools with different devices & - Standardization of the content \\
- Professional development of teachers & - Parent's interfere \\
- New jobs in design content & - Students privacy \\
- Students' equity of using new technology & \\
- Mitigate of teachers' daily difficulties & \\
- Cooperation with local universities & \\
- Share ideas and experience with technology & \\
\hline
\end{tabular}


Students' assessment is crucial point in the Palestinian education system, it could be developed by cooperating with local universities and international organizations to achieve the global standardization of assessment. Moreover, due to the lack of high-quality content and credible organizations, parents' interference could increase and potentially threaten the Smart Learning project. To overcome such weaknesses and threats, teachers and principals should be involved in decision making for implementing the SL project.

RQ2: In terms of the second research question which was about the changes that took place in the learning environment because of implementation of Smart Learning project in the Palestinian schools. The findings of the study revealed changes in six dimensions including school principals' roles, teachers' roles, new pedagogical approaches, students' roles, curriculum, and learning space.

\section{Schools' principals}

In Palestinian principals are responsible for implementation of technology for instructional purposes. They are authorized to lead the entire school. Therefore, for effectiveness, principals need a clear vision for the implementation of technology for instruction and a vision that how it can enhance the learning process of their students. Principals are the initiaters of novel technology \& pedagogical practices in their schools.

Schools' principals are engaged in many workshops funded by USAID to recognize the power of technology to enhance the skills and productivity of teachers and students as well to build their schools mission and vision of implementing SL program.

Based on principals and teachers' interviews and focus group sessions, most of the principals lead the development and implementation of SL project in their schools. The principals urged to collaborate with teachers to involve in the SL project effectively. Most of the principals reported that they believe that teachers should be involved in strategic planning initiatives in their schools to enhance technology use in education. Below are the roles that school principals play to transform their schools to implement SL effectively:

\section{Developer technology culture}

Most of the principals of the schools visited by the researchers reported that they build a professional culture of teaching with technology in their schools by cooperating with teachers in the schools and the local community. The principals mentioned that they develop a technology culture based on their teachers' needs and interests.

Before the beginning of the academic year, I met with the teachers in my school to develop a plan for technology integration in my school... Teachers input was invaluable for me because at the end they will lead the innovative in the schools [Principal A, QD].

Another principal mentioned that local community is important to support the project financially and it's important to share with them our mission in terms of implementing the SL project to get their input [Principal B, ND].

In the focus group discussion sessions, teachers reported that school's administrators build a comfortable environment for using technology in teaching. School's administrators encouraged collaborative work among teachers to use technology in teaching. 
Technology culture was ensured by the principals through providing financial support to maintain and update the SL project.

Principals support the exchange visits with success schools in using technology in the same region or in different one. To encourage technology use among the teachers and to raise awareness, many schools' principals mentioned that they sponsored various domestic tours for the teachers to share their experience of SL with their peers in different schools.

Last month, the science and math teachers went to visit their peers in different schools... They shared with each other their activities for technology integration [Principal C, JD].

In the focus group discussion, many teachers mentioned that school's administrators encouraged them to integrate technology into their practice and support them to attend professional development workshops.

He always encouraged me to use technology in my class.... He supported me to attend workshop training related to technology integration especially about Interactive board [Teacher S, TD).

Principals wishing to implant a positive technology culture in the school must make their aims clear to all through the processes that take place on daily basis.

Most of the teachers in the study mentioned that they got support from their schools' principals by equipping schools with new tools and facilitating technology integration the classroom.

In each meeting, the principal encourages us to use technological resources in our classroom... He is open mind to discuss with him our need for technology integration in the class [Teacher S].

\section{Leadership}

Most of the teachers in the schools visited during the tenure consider their principals to be the powerful definers of the culture, character, and organization of their schools through working with individuals. Other teachers mentioned that principals can build the momentum and involve others in the process of change in their schools.

Many of the teachers mentioned that the leadership does not come only from the principal, but teachers can play decisive role in the educational leadership to lead technology implementation in the schools.

On the other hand, principals claimed that leadership often begins with establishing a vision and providing clear expectations for teachers but continues as support and guidance for teachers' technology use in the classroom.

Evidence gathered from classroom observations and schools visits show that most teachers had little prior experience of the technological activities they were asked to perform especially by using interactive projectors. In each of the observed schools, the principal, technology teacher, and peers always come to classroom on demand to provide support, suggestions, and encouragement. 
The leadership involves solving daily challenges regarding use of technology in the schools. In each of the schools, technical support, infrastructure, instructional assistance, time, funding, and staff were limited. Strong leadership collaboration with MOEHE and local community found solutions to allow change and innovation to take place, with the available resources. In many cases it was found that principals coordinate with the local community to support the project financially to overcome the challenges especially technical one.

Schools have different viewpoints on educational leadership. Some schools have an approach to involve some type of collaborative management composed of teachers, local community, and the school administrators to lead the SL project.

Having a collaborative leadership in the school will help teachers to maximize their skills and will be effective in their technology integration.... It helps us to create powerful and successful change for developing the new project

[Principal F, RD].

\section{Generating a technology integration policy}

Many of Principals reported that their role shifted from a technology infrastructure focus to a technology integration focus to strengthen the process of teaching and learning and to achieve efficient school management in the SL project.

I have changed my focus from technology infrastructure to technology integration... Technology infrastructure is the responsibility of the ministry and the directorate... supporting teachers in the SL environment is important and it is the first order responsibility [Principal G, HD].

In the implementation of SL project, it is important to have a policy to hold together the ways in which technology is involved in educational activities. Half of the schools' principals developed a technology policy with teachers in their schools to implement SL project in teaching practice. Teachers reported that principals share the values envisioned within the SL and that they understand its implications. The principals considered the policy as an important part of development and implementation of SL in teaching.

In my school, all teachers involve in the development of technology integration policy and reflect on it based on his/her needs...Individual inputs make the technology policy [Principals I, JD].

\section{Teachers' roles}

Both principals and teachers described two kinds of teachers who were teaching during the implementation process of the SL project, these teachers were labeled by the researchers as innovative teachers $(42.3 \%)$ and instrumental teachers (57.7\%). Teachers reported that their perceptions of SL program have an influence on their teaching styles and practice in the classroom.

Teachers' role is changing based on the topic and the grade. We observed in many schools that teachers were facilitator of the learning in the class especially in science when 
they used the exploration learning strategy with students. In the focus group sessions, teachers reported that they knew about the best practice of SL in other schools from social media websites or through visiting their schools which has a positive influence on them to change their roles. There was agreement among teachers that their main roles are planning and providing electronic content for learners and creating healthy relationship among learners and teachers. Not only teachers' roles changed in the SL program, but also, some changes occurred in teacher attitudes, knowledge and behaviors were identified, consisting of: a shift in beliefs about how students learn, a deeper understanding of new teaching strategies, changes in student learning activities and changes in how technology was used to promote learning, including an increase in classroom management and access to open educational resources that resulted in more student time on task. Based on the classroom observations, participant's interviews, and focus group discussion, the researchers observed different roles teachers play in the classroom while using different technology tools. Table 2 summarizes the teachers' roles in SL environment observed in the schools visited during data collection. Each role is associated with specific set of activities and is made possible using technology in support of different new teaching methods such as inquiry-based learning and learning by exploration based on the topic and the grade teacher teaching. However, we categorized teachers into two main categories according to the change into their roles including instrumental and innovative teachers.

\section{Traditional teachers}

are defined by the researchers and described by the participants as those who did not change their beliefs about their role after the implementation of the SL project in their classroom and consequently, did not change their teaching style.

Table 2 Summarizes the teachers' roles in SL environment observed in the schools visited during data collection

\begin{tabular}{|c|c|c|c|}
\hline Category & Theme & \multicolumn{2}{|l|}{ Subtheme } \\
\hline $\begin{array}{l}\text { Traditional } \\
\text { Teachers }\end{array}$ & \multicolumn{3}{|c|}{$\begin{array}{l}\text { Teachers who believes that technology does not have any impact on teachers and it converts the } \\
\text { curriculum from text into visualization mode. }\end{array}$} \\
\hline \multirow[t]{8}{*}{$\begin{array}{l}\text { Innovative } \\
\text { Teachers }\end{array}$} & \multirow[t]{4}{*}{$\begin{array}{l}\text { Instructional } \\
\text { Roles }\end{array}$} & $\begin{array}{l}\text { Facilitator } \\
\text { (Advisor) }\end{array}$ & $\begin{array}{l}\text { Give assistance and advice for students to finish their projects. } \\
\text { Promote interactions among students, encourage participation, } \\
\text { and facilitate discourses }\end{array}$ \\
\hline & & $\begin{array}{l}\text { Instructional } \\
\text { Designer }\end{array}$ & $\begin{array}{l}\text { Use available resources to enrich the lesson activities/design } \\
\text { activities individually/design team }\end{array}$ \\
\hline & & Collaborators & $\begin{array}{l}\text { Collaborate with colleagues to design activities or share ideas } \\
\text { with them }\end{array}$ \\
\hline & & Team Teaching & $\begin{array}{l}\text { Teachers together set goals for a unit from curriculum to teach } \\
\text { it with technology, prepare individual lesson plans, teach } \\
\text { students, and evaluate the results. }\end{array}$ \\
\hline & $\begin{array}{l}\text { Technological } \\
\text { roles }\end{array}$ & Trainer & $\begin{array}{l}\text { Support learners to use technologies/Modeling the use of } \\
\text { technology to complete the project/provide support to students }\end{array}$ \\
\hline & \multirow[t]{2}{*}{ Social Roles } & \multirow[t]{2}{*}{ Communicators } & $\begin{array}{l}\text { Support social interaction and } \\
\text { Collaboration }\end{array}$ \\
\hline & & & Creating friendly and comfortable social environment \\
\hline & $\begin{array}{l}\text { Organizational } \\
\text { roles }\end{array}$ & $\begin{array}{l}\text { Team } \\
\text { coordinator }\end{array}$ & $\begin{array}{l}\text { Negotiating an agenda for learning activities; timetabling } \\
\text { learning activities and tasks; clarifying procedural rules } \\
\text { and decision-making norms. }\end{array}$ \\
\hline
\end{tabular}




\section{Innovative teachers}

those who have adopted the role of coach. Teachers indicated that using tablet devices had changed the teaching style and a wider range of learning activities could be organized (e.g. integrating multimedia and developing interactive exercises).

Teachers argue that their changing role makes teaching quite exhausting on the one hand, but more interesting on the other hand.

\section{Emerged new pedagogy}

Through observing classrooms in different schools, various teaching methods were observed including project-based learning (science and math), flipped classroom (Arabic, English, science), learning by doing (science, English), and drama in education (Arabic, English), resources-based learning (English, science), game-based learning (math), learning by exploration (science, math, technology).

The findings of the study revealed that teachers are not only using real experiments to convey knowledge to their students in different topics, but also exploring the use of different technologies integrated with new pedagogy to involve their students in the learning process. Teachers in the study reported that they employed diverse pedagogical techniques based on their students' needs and on the learning situation to achieve specific learning goal(s). Our observations emphasized teachers' claim and we documented challenges of using more than one teaching method into classrooms.

Figure 2 illustrates the frequency of using the pedagogical types in five topics (Science, Mathematics, Arabic, English, and Technology) being observed in the classroom teaching. Teachers integrated technology carefully with state of the art teaching methods to support lesson goals and activities.

Teachers played different roles while utilizing the novel teaching methods. Lesson planning in the SL is improved to include more details about the description of the activities and teaching methods. Figure 2 represents the frequency of using new pedagogy in each topic.

Apart from pedagogy changes in the Palestinian system, teachers use new methods of assessing their students whether they acquired new skills or not. The new assessment

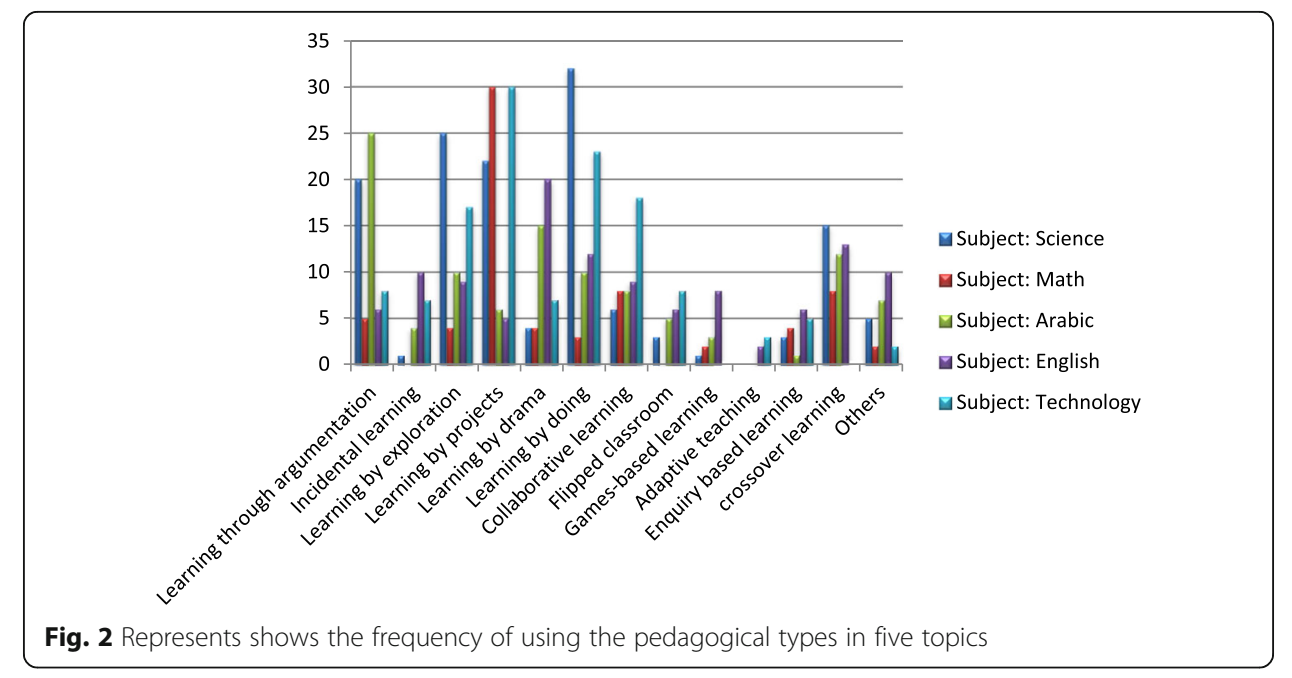


methods were synchronous with teacher's pedagogy. For example, in the collaborative work, teachers used three types of assessing students including peer-assess, feedback, and rubric. Even though, traditional exams and quiz are still the main methods of assessing students in the Palestinian educational system. The researchers did not predict huge changes in student's assessment in the SL project.

\section{Students role}

In the current study, students' role is less focused in the learning process, but we observed some emerging roles for students by using new strategies such as researcher, productive, negotiator, and presenter. This made shift in the student role from passive to active as reported by the teachers.

These roles emerged due to student-centered learning and using novel pedagogical techniques which transfer the students from passive mode into active one.

Sometimes, I asked my student to prepare a presentation or a job ad to help me in the class...Students play active role in the collaborative work in math [Teacher M, SD].

In some cases, we observed that students need guidance to use specific strategy such as learning by exploration in the science lab. Students needs to be prepared to work together especially in the collaborative learning strategy.

\section{Curriculum}

The Ministry of Education in cooperation with national and international organizations are still working on development of interactive content and to replace the paper books with digital ones. Some local companies are investing in developing interactive content but it is still trial.

Teachers design their interactive content/activities individually or within team design, but this is still in the earlier stage of designing suitable digital content for the whole country and it is individual initiative.

\section{Learning spaces}

Through implementation of in-class activities, teachers re-organize the classroom settings to be suitable for the teaching methods used in the class. Most of the math and science teachers changed the classroom shape. For example, math's teachers reshaped the classroom to be suitable for the team work, project-based learning, and collaborative learning strategies. One teacher said, it is important to change students' seats to facilitate learning by projects. Another teacher mentioned that "re-organizing students' seats send messages to students about how the class activities will occur" [Teachers M, SH]. Normally, students are set in row and line. Three changes of classroom setting including U-shape for science lab, table-group for group working, and students learning on their own space out of classrooms..

The classroom designs are central for improving communication, collaboration, interaction and engaging within the classroom both from instructor and learner perspectives. In particular, the hybrid arrangement is reflective of the instructional paradigm where collaboration is encouraged. Adjustment of learning space and 
learning experiences should go hand-in-hand with re-conceptualizing technologically enhanced learning spaces that complement paradigm shift. It is essential to have flexible classroom environments that support integration, engagement and collaboration among instructors and learners without regard to location.

The classroom setting sends messages to students about learning and how learning will occur in the space.

\section{Discussion}

On the basis of data analysis of smart learning project teachers' practice of digitalization in the schools involved in the project has been delineated. SL can be described as the learning that includes the interaction between learners and environments as well as integrates technology with new teaching methods to make students qualified in work place with focus on professional development of teachers which is congruent with previous studies (Hwang, 2014; Zhu et al., 2016).

There were differences among schools in Palestine regarding implementation of the SL project. It is obvious that some schools have managed to implement SL successfully compared with other.

schools despite of the drawbacks faced due to financial, social, technological, and cultural difficulties existing in Palestine. The MOEHE needs to develop understanding strategy for implementation of SL and to have a clear plan to transfer from traditional pedagogy into smart one. Therefore, MOEHE needs to be flexible and capable of adapting these new paradigms with clear vision. A new teaching methodology must be developed to facilitate discussions, probe questions, encourages students to think and stimulate creativity.

Gross (2016) mentioned that smart learning consists of advanced infrastructure, rich, fun content that can taught in an individualized manner which are concurrent with the finding of the study Wide spread mobile devices enables learning in the technology era to be everywhere, easy to use, and has rich content, high efficiency, flexibility, security, reliability, interactivity, portability, and other features that can be used to compete with other teaching methods.

Adaptable learning strategies, tools, and resources can be adjusted to learner's profile by identifying learner's characteristics and teachers design their activities based on their learner's needs. Teachers reported that they used different methods to identify their learners' style and needs including questionnaires, and exams.

According to the research findings, the use of technology changes the role of the teacher from a primary source of information into secondary source of information and a facilitator guiding the students' learning processes which is congruent with previous studies (Attaran, Alias, \& Siraj, 2012; Groff, 2013).

Changing teachers' role in the SL project depends on local school conditions. The actual situation of the school (school culture, school environment, etc) affects the integration of technology into teaching and learning practices. For example, there is a huge difference among the main two parts of Palestine (Gaza and West Bank). Public schools in both sides belong to MOEHE, but the differences between implementing of the project depend on the school environment and political issues which we cannot discuss it in a scientific journal. 
In particular, the importance of the principal, who can guide the technology implementation by scaffolding teachers (Montrieux et al., 2015), adequate school ICT-support (Bingimlas, 2009) and school ICT infrastructure (Hinostroza, 2018) need to be considered during technology innovation into classrooms. Teachers must plan to be facilitators who provide scaffolding to support students in developing their own personal ways of knowing and thinking.

Thinking, problem solving, collaborating and communicating must emerge onto center stage of SL project and provide the means for all students, not just a select handful, to traverse this multi-disciplinary landscape.

Designing technology-integrated learning will continue playing a crucial role. Teacher-related factors such as confidence, attitudes toward technology integration, and willingness to undertake a change incorporating technology use for student learning (Levin \& Wadmany, 2008) are hallmarks of this century's best teachers.

The seating arrangement can depict a message about power and control and how communication is going to take place. Room arrangement also has an impact on students' expectations about learning. Harris and Cullen (2010) reviewed three seating arrangements and the preference toward learning. The three classroom settings which were U-shape, traditional, and group seats transmit different messages to students regarding their role as learner, and each setting promotes a different communication pattern in the classroom.

\section{Conclusion}

In this paper, we examined the strengthens and weaknesses of the Smart Learning project in Palestine and explored the changes associated with the implementation of the project in the middle schools.. The project has different strengthens and weaknesses as well as it provides many oppurtunities for the local companies and local community to support the educational system. The smart Learning project has several important positive influences on the components of the Palestinian educational system including students, teachers, school's administrative, and curriculum. The MOEHE should focus more on developing appropriate content as well as to develop a guideline for various smart learning activities.

\section{Limitation of the study}

There are certain factors that are probable reasons of strength and weakness of projects. The relationships among those factors are out of scope of this study. Furthermore in depth investigation of student's role is yet to be done.

Abbreviations

ICT: Information and Communication Technologies; LTD: Leadership and Teacher Development program; MOEHE: Ministry of Education and Higher Education; SL: Smart Learning; u-learning: Ubiquitous Learning

\section{Acknowledgements}

We would like to thank schools principals and teachers in schools for their cooperation to finish the study. Furthermore, we would like to thank our colleagues for their support and feedback to improve the study. 
1. We informed the participants of the study that all the raw data, field notes, and pictures will not publish to the public through any source of technology.

2. All data in Arabic language.

3. To get a permission from the Ministry of education in Palestine, we informed them the data, and material will be for the researchers use and will not be published on any repository.

\section{Authors' contributions}

Data were collected by the first author because he is native in Arabic language and started to analyze data and discuss it with the second author. The contribution of the second author was designing the research and the discussion section. Both of the researchers meet virtually to discuss the process of data analysis and the findings. All authors read and approved the final manuscript.

\section{Competing interests}

The authors declare that they have no competing interest.

\section{Publisher's Note}

Springer Nature remains neutral with regard to jurisdictional claims in published maps and institutional affiliations.

\section{Author details}

${ }^{1}$ Instructional Systems Technology, Indiana University, Bloomington, USA. ${ }^{2}$ Department of Computer Science, Bahauddin Zakariya University, Multan, Pakistan.

Received: 12 June 2018 Accepted: 31 July 2018

Published online: 22 August 2018

\section{References}

EL Adu, \& DCC Poo, Smart learning: A new paradigm of learning in the smart age. Paper presented at TLHE 204: International conference on teaching and learning in higher education. National University of Singapore. (2014) Retrieved from: http://www.cdtl.nus.edu.sg/Tlhe/tlhe2014/abstracts/aduek.pdf:

M Arif, M Illahi, A Karim, S Shamshirband, KA Alam, S Farid, VE Balas, An architecture of agent-based multi-layer interactive e-learning and e-testing platform. Qual Quant 49(6), 2435-2458 (2015)

M Attaran, N Alias, S Siraj, Learning culture in a smart school: A case study. Procedia Soc Behav Sci 64, 417-423 (2012)

KA Bingimlas, Barriers to the successful integration of ICT in teaching and learning environments: A review of the literature. Eurasia J Math Science Technol Educ 5(3) (2009)

A Dubey, Towards adopting ODC in automation application development projects. In Proceedings of the 5 th India Software Engineering Conference (pp. 153-156). ACM (2012)

ESOMAR. Global Market Research 2017: ESOMAR Industry Report. ESOMAR. (2017). Retrieved from: https://www. activaonline.cl/zip/activa/20180122105033_ESOMAR_Global-Market-Research-2017.pdf.

S Farid, R Ahmad, M Alam, A Akbar, V Chang, A sustainable quality assessment model for the information delivery in Elearning systems. Inf Discov Delivery 46(1), 1-25 (2018). https://doi.org/10.1108/IDD-11-2016-0047

S Farid, M Alam, G Qaiser, AAU Haq, J Itmazi, Security threats and measures in E-learning in Pakistan: A review. Tech J 22(3), 98-107 (2017)

R Felton, A question of SWOT. Met Pow Rep 7(59), 3 (2004)

TEA Galil, The Mohammed bin Rashid's Smart Learning Program (SLP) Initiative in the Ministry of Education and its impact on English language performance in Cycle2 Classes, in the United Arab Emirates (UAE) (Doctoral Dissertation, The British University in Dubai (BUiD)). (2014)

J Groff, Technology-rich innovative learning environments. OCED CERI Innovative Learning Environment project, 1-30. (2013)

B Gros, The design of smart educational environments. Smart Learning Environment 3(15) (2016). https://doi.org/10 1186/s40561-016-0039-x

M Harris, \& RM Cullen, Leading the Learner-Centered Campus: An administrator's Framework for Improving Student Learning Outcomes. San Francisco, CA: Jossey-Bass. (2010)

JE Hinostroza, in In ICT-Supported Innovations in Small Countries and Developing Regions (Pp. 99-119). New Challenges for ICT in Education Policies in Developing Countries: The Need to Account for the Widespread Use of ICT for Teaching and Learning outside the School (Springer, Cham, 2018)

GJ Hwang, Definition, framework and research issues of smart learning environments-a context-aware ubiquitous learning perspective. Smart Learning Environments 1(1), 4 (2014)

MS Ibrahim, AZA Razak, HB Kenayathulla, Smart principals and smart schools. Procedia Soc Behav. Sci 103, 826-836 (2013)

RH Kay, Examining gender differences in attitudes toward interactive classroom communications systems (ICCS). Comput Educ 52(4), 730-740 (2009)

Z Khlaif, Teachers' perceptions of factors affecting their adoption and acceptance of mobile technology in K-12 settings. Comput Sch 35(1), 49-67 (2018b)

ZN Khlaif, Factors influencing teachers' attitudes toward mobile technology integration in K-12. Technol Knowl Learn 23(1), 161-175 (2018a)

T Kim, JY Cho, \& BG Lee, Evolution to Smart Learning in Public Education: A Case Study of Korean Public Education. In Open and Social Technologies for Networked Learning (Pp. 170-178). Springer, Berlin, Heidelberg (2013).

NSC Kinshuk, IL Cheng, Evolution is not enough: Revolutionizing current learning environments to smart learning environments. Int. J. Artif. Intell. Educ. 26(2), 561-581 (2016)

TS Koh \& SC Lee, Information Communication Technology In Education: Singapore's ICT Masterplans 1997-2008. (2008) 
T Levin, R Wadmany, Teachers' views on factors affecting effective integration of information technology in the classroom: Developmental scenery. J Technol Teach Educ 16(2), 233 (2008)

D Liu, R Huang, \& M Wosinski, Contexts of smart learning environments. In Smart Learning in Smart Cities (pp. 15-29). Springer Singapore (2017).

M Mikki, \& N Jondi, eLearning in Palestine. U. Demiray, Cases on challenges facing e-learning and national development: Institutional studies and practices, 2, 627-652 (2010)

MOEHE, Education Development Strategic Plan EDSP Plan 2014-2019, A Learning Nation (Ministry of Education and Higher Education, Ramallah, 2014)

MOEHE, Third national strategic plan 2017-2022 (Ministry of Education and Higher Education, Ramallah, 2017)

H Montrieux, R Vanderlinde, T Schellens, L De Marez, Teaching and learning with mobile technology: A qualitative explorative study about the introduction of tablet devices in secondary education. PLoS One 10(12), e0144008 (2015)

Palestine Ministry of Education and Higher Education (MoEHE), Assessment 14: The Effect of the Israeli Occupation on Palestinian Education from 28/9/2000-3/11/2004. Ministry of Education and Higher Education, Ramallah, Palestine 2004.

PALESTINIAN MINISTRY OF EDUCATION. Special report, July, Palestinian National Authority Official. Website [On-line]. 2000. Available: http://www.pna.net/reports/edu_in_pal.html

M Risler, E-learning curriculum in Palestinian primary and secondary education (Belgian technical cooperation report) (Unpublished report, Ramallah, Palestine, 2009)

S Saidam, in In ICEGOV2007. Knowledge and e-governance building in conflict affected societies: Challenges and mechanisms (ACM, Macao, China, 2007)

P Serdyukov, P Serdyukov, Innovation in education: What works, what doesn't, and what to do about it? J Res Innovative Teach Learn 10(1), 4-33 (2017)

K Shraim, Z Khlaif, An e-learning approach to secondary education in Palestine: Opportunities and challenges. Inf Technol Dev 16(3), 159-173 (2010)

JM Spector, Conceptualizing the emerging field of smart learning environments. Smart Learn Environ 1(1), 2 (2014)

Z Taleb, F Hassanzadeh, Toward smart school: A comparison between smart school and traditional School for Mathematics Learning. Procedia Soc Behav Sci 171, 90-95 (2015)

J Woollard, Psychology for the classroom: E-learning Routledge (2011)

ZT Zhu, MH Yu, P Riezebos, A research framework of smart education. Smart Learn Environ 3(1), 4 (2016)

\section{Submit your manuscript to a SpringerOpen ${ }^{\circ}$ journal and benefit from:}

- Convenient online submission

- Rigorous peer review

- Open access: articles freely available online

- High visibility within the field

- Retaining the copyright to your article

Submit your next manuscript at $\boldsymbol{s p r i n g e r o p e n . c o m ~}$ 